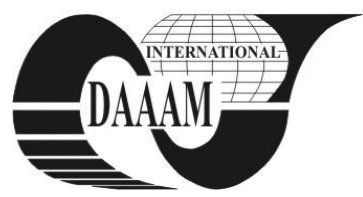

Annals of DAAAM for 2011 \& Proceedings of the 22nd International DAAAM Symposium, Volume 22, No. 1, ISSN 1726-9679 ISBN 978-3-901509-83-4, Editor B. Katalinic, Published by DAAAM International, Vienna, Austria, EU, 2011 Make Harmony between Technology and Nature, and Your Mind will Fly Free as a Bird Annals \& Proceedings of DAAAM International 2011

\title{
ENVIROMENTAL SUSTAINABILITY AND GRAPHIC PRODUCTION
}

\author{
BOLANCA MIRKOVIC, I[vana]; MAJNARIC, I[gor] \& BOLANCA, S[tanislav]
}

\begin{abstract}
The research results on the influence characteristics of graphic materials and conditions in printing on the print quality and efficiency of the recycling are presented in this paper. Research was carried out in the field of offset printing and digital printing based on electrophotography with liquid and solid toner. Comparing the results through the segment of gamut volume and the recycling efficiency of prints a certain correlation in which the variable conditions in the printing have an important role were noticed. Obtained results justify further research in the direction of environmentally friendly materials and processes across the lifecycle of graphic products, including the settings of industrial ecology and sustainability.
\end{abstract}

Key words: offset printing, digital printing, gamut, recycling, image analysis

\section{INTRODUCTION}

The concept of environmental sustainability refers to the systematic conditions that should not be disturbed by human activities either at a global or regional level more than the planet allows. At the same time all the natural resources must not be depleted, and have to be sufficient for the next generations. These two requirements should be in balance with the third one regarding sustainability which refers to the principle of ethics and fairness (Halada, 2003). Environmental awareness, health and safety factor have an important role in identification of printing technologies for the future (Moberg, 2010). In order to increase effectiveness of resource usage and effectiveness of environmental management system, life cycle assessment of the product has to be considered and included in planning and projecting, starting from early stage of design (Kadam, et all.2009). The purpose of this paper was to review environmental aspects of printed products through certain segments of the life cycle within the issues of environmental sustainability. Since the different materials and processes focusing on those ecologically suited were used it is important to determine the reproduction quality, and then continue to follow a life cycle with special reference to its last phase. Significant contribution of research is explanation and combining the impact of printing conditions on the efficiency of prints recycling with the aim of obtaining results with applications in the field of environmentally suitable materials and processes taking into account the environmental sustainability settings.

\section{EXPERIMENTAL}

The samples of colour prints are obtained by the offset printing with ink with higher share of renewable raw materials, (Heidelberg sheet fed machine), indirect electrophotography with liquid toner (Turbo Stream HP Indigo machine) and electrophotography printing with dry toner (Xerox DocuColor 5000 machine). The test form contained different printing elements: standard CMYK step wedge in the range from 10$100 \%$ tone value, standard ISO illustration for the visual control, textual positive and negative microelements, wedges for determination the greyness and the standard wedge with 378 patches for production of ICC profiles and 3D gamut. The unique test form was used in printing. The prints were made on the fine art paper and the wood free natural paper. In offset printing process the conventional and model ink with renewable raw materials has been used.

The recent investigations have proved the bad effectiveness of print recycling made in the indirect electrofotographic printing with liquid toner and therefore the series of prints made with changing the conditions in this printing technique. For prints recycling the method of alkaline chemical deinking flotation was used, which was described in details in the previous work (Bolanca Mirkovic, 2009). The handsheets were made using a laboratory sheet former, according to standard method T 205. The spectrophotometric analysis was made with X-Rite SwatchBook and ColorShop 2.6 application. From ICC profile with the use of MONACO Platinum programe the gamut of prints is established. Residual specks, toner number and area were assessed with image analysis software Spec*Scan, Apogee System. This system is utilizing scanner to digitize image. Threshold value (100), white level (75) and black level (65) were chosen after comparing computer images to handsheet.

\section{RESULTS AND DISCUSSION}

As an indicator of reproduction quality two dimensional and three-dimensional reproduction gamuts were used (Fig. 1).
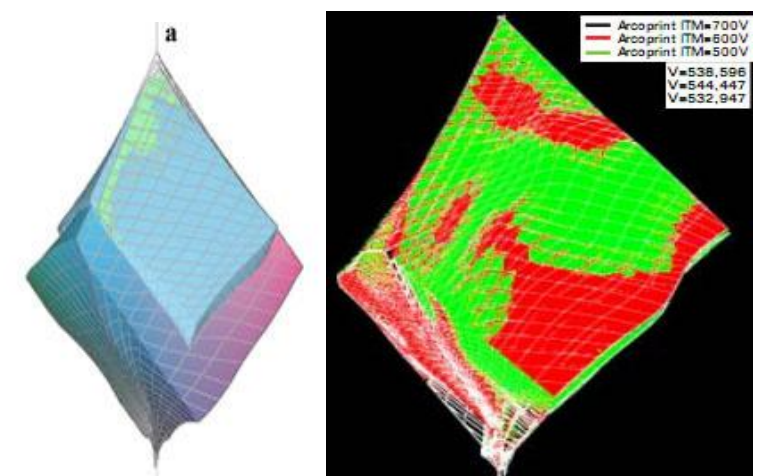

Fig. 1. Gamut of prints: a) indirect electrophotography with liquid toner and offset printing with conventional ink and ink with higher share of renewable raw materials, b) indirect electrophotography with a liquid toner with offset cylinder voltage of 500,600 and $700 \mathrm{~V}$

Indirect electrophotography print with ElectroInk compared with the offset print made with the higher share of renewable raw materials in the ink has larger gamut. The differences in gamut volume $\Delta \mathrm{VCIE}{ }^{*} \mathrm{a} * \mathrm{~b} * \mathrm{CCU}$ of calibrated standard offset prints and indirect electrophotography with liquid Indigo toner amounts below 2.0 spatial units. Considering that in electrophotography for a better transfer of ink from the 
photoconductor to the medium a positive offset cylinder charging is necessary for the reproduction gamut due to voltage from $+500 \mathrm{~V}$ to $+700 \mathrm{~V}$ are shown. Largest gamut reproduction was achieved with $+600 \mathrm{~V}$ voltage of offset cylinder (V CIE L $*_{\mathrm{a}}$ *b $* \mathrm{CCU}$ is 544.447 spatial units), while the lowest voltage is achieved with a $+500 \mathrm{~V}$ (532.947 spatial units). Discussed prints are made on woodfree uncoated offset paper. To determine the substrate influence a series of prints on coated art paper for printing were made. Prints on the fine art paper by changing the voltage of offset cylinder have a larger gamut volume than the prints on the uncoated offset paper. At the voltage of the offset cylinder of $+500 \mathrm{~V}$ difference of gamut volume $\triangle \mathrm{V}$ CIE L $* \mathrm{a} * \mathrm{~b} * \mathrm{CCU}$ is 211,277 spatial units. The largest gamut volume is achieved with voltage of $+700 \mathrm{~V}$ (CIE $\mathrm{L} * \mathrm{a} * \mathrm{~b} * \mathrm{CCU}=781,947$ spatial units).

Given that one of the research goals is in the domain of the last phase of the printed products life cycle, which are known for their poor recycling, it is important to determine the relation of conditions in the press, print quality and characteristics in the area of post consumer waste disposal with the aim of achieving cradle to cradle" closed-loop.

The Fig.3 shows the dirt content histograms handsheets made from the fibers after the deinking flotation of prints made with various printing techniques in certain process conditions and in one segment of the application of environmentally acceptable inks. All prints are made on uncoated paper.

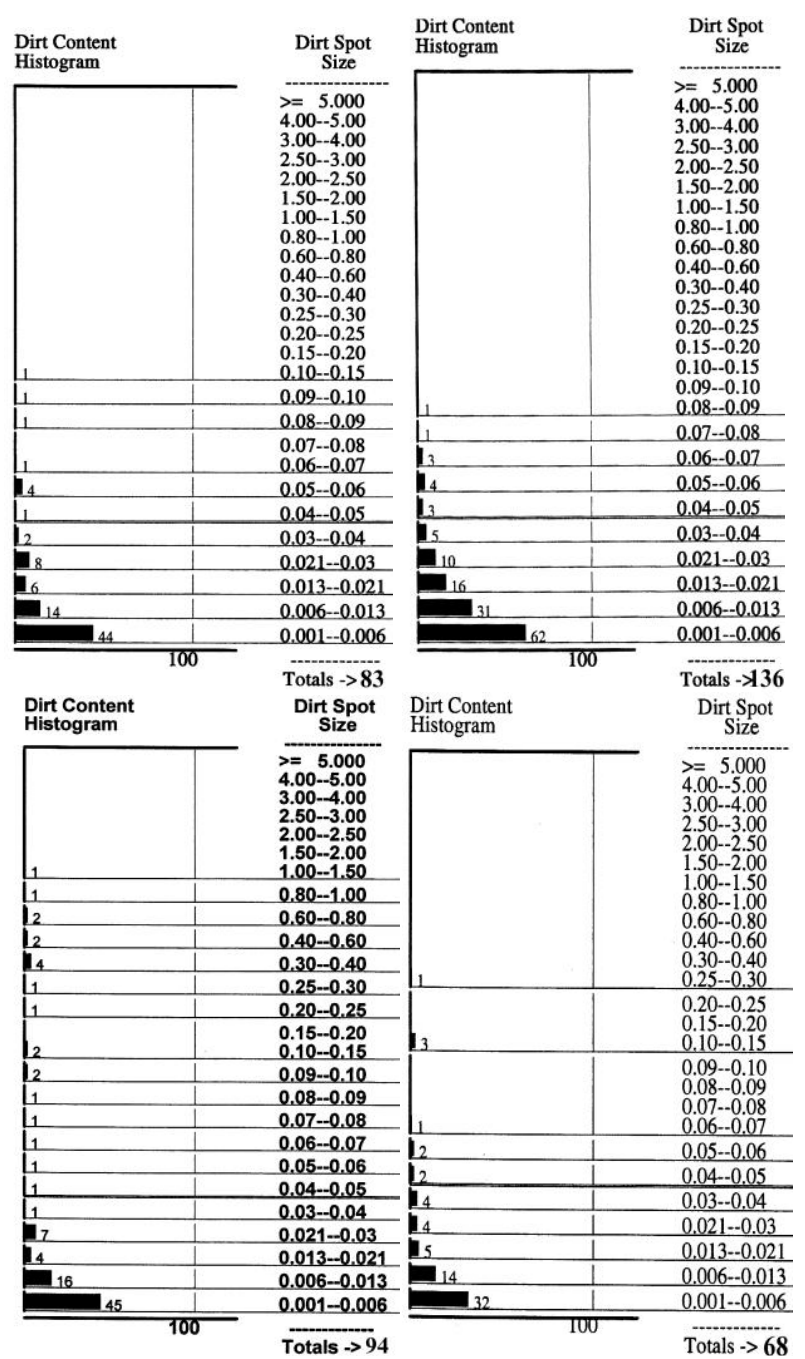

Fig. 3. Dirt content histogram: a) conventional offset printing ink b) offset printing ink with a higher share of renewable raw materials c) indirect electrophotographic printing with liquid toner with the voltage of the offset cylinder $+600 \mathrm{~V}, \mathrm{~d}$ ) electrophotographic printing with solid toner; substrate: uncoated paper
The results show that the sheets made from recycled fibers from offset prints have most specks in classes of less than 0.04 $\mathrm{mm}^{2}$. In the dirt spot size greater than $0.01-0.15 \mathrm{~mm}^{2}$ neither one particle was measured. Increasing renewable raw materials for offset ink also increased the number and specks area, while the trend in the distribution of specks inside the dirt spot size remained its characteristics. Handsheet made from recycled fibers of indirect electrophotography at $+600 \mathrm{~V}$ voltage of the offset cylinder contain a total of fewer specks, but a larger area. This is otherwise recycling characteristic of such prints compared to the prints of other printing techniques. Using the described experimental conditions specks does not exceed the class 1.00 to $1.50 \mathrm{~mm}^{2}$ what is a certain achievement in the relation to the previous results (Bolanca Mirkovic, 2007).

Handsheets made from recycled fibers from prints based on electrophotography with solid toner contain a small number of smaller areas specks. Such prints are characterized by greater efficiency in recycling compared to prints made with liquid toner electrophotography. One of the major factors of the recycling efficiency is a type of printing substrate. The results indicate a somewhat lower efficiency of recycling compared to uncoated paper. On uncoated paper the adhesion of printing ink to paper depends on paper properties such as surface structure, fiber type, ash content and drying mechanism of the chosen printing process. Printing inks which form firmly sticking, example offset inks containing large shares of oxidative drying oils such as linseed oil or soy oil. Except the earlier mentioned, the fact must be acknowledged that the coating process assists in dispersing the fillers in the coating. In a recycling process at time dispersants are surface active and together with alkaly can lead to acceptable ink detachment from the coated paper. These species can hydrophilise ink containing agglomerates and hinder flotation efficiency.

\section{CONCLUSION}

The research results give an answer in the relation between the characteristics of graphic materials, the printing conditions, print quality and characteristics in the area of recyclable print waste process. Comparing the results through the offset print gamut volume segment and the one based on electrophotography with liquid toner it may be concluded that there is a growing convergence when it comes to environmentally favorable materials.Comparing the results of the gamut volume segment and the efficiency of the prints recycling a certain correlation, in which tested conditions in the press have an important role, was noticed.

Obtained results justify further research in the direction of environmentally friendly materials and processes across the lifecycle of graphic products, including the settings of industrial ecology and sustainability.

\section{REFERENCES}

Kadam, S., R., Even, S., M., E., Rothenberg, S., (2009) A comparative study of the environmental aspects of litographic and digital printing processes, GATF, Rochester

Bolanca Mirkovic, I., (2007) Ecologically suitable offset inks and mechanism of the prints deinking, PhD Dissertation, Faculty of Graphic Arts ,Zagreb

Bolanca Mirkovic, I., Majnaric, I., Bolanca Z., \& Grgasovic, A., (2009). Recycling of waste paper with different density of liquid toner, Proceedings of the $20^{\text {th }}$ International DAAAM Symposium, November 2009 Vienna, ISBN 1013982 Katalinic, B. (Ed.), pp. 075-077, Pablished by International Vienna, Vienna

Moberg, A., (2010) Assessment of media and communication from a sustainability perspective, $\mathrm{PhD}$ Dissertation Royal Institute of Technology Stockholm

Halada, K., (2003) Progress of ecomaterials toward a sustainable society Current Opinion in Solid State and Materials Science, 7,209-215 